\title{
Retraction Note to: Numerical simulation on pollutant dispersion from vehicle exhaust in street configurations
}

\author{
Mohamed F. Yassin • R. Kellnerová • Z. Jaňour
}

Published online: 6 December 2016

(C) Springer International Publishing Switzerland 2016

\section{Retraction Note to: Environ Monit Assess (September 2009) 156:257-273 \\ DOI 10.1007/s10661-008-0482-4}

This article has been retracted at the request of the Editor-in-Chief. A complaint received against it indicated that significant sections of the text showed a similarity with the authors own papers published previously. The two papers are:

1. Impact of street intersections on air quality in an urban environment, Mohamed F. Yassin, R. Kellnerovác, and Z. Jaňour, Volume 42, Issue 20, June 2008, Pages 4948-4963. Atmospheric Environment
The online version of the original article can be found at http://dx. doi.org/10.1007/s10661-008-0482-4.

\footnotetext{
M. F. Yassin $(\bowtie)$

Department of Environmental Technology Management, Kuwait University, P.O. B5969, Safat 13060, Kuwait

e-mail: mohamed_f_yassin@hotmail.com

M. F. Yassin

Faculty of Engineering, Assiut University, Assiut 71516, Egypt

R. Kellnerová $\cdot$ Z. Jaňour

Institute of Thermomechanics AS CR, Prague, Czech Republic

M. F. Yassin

Department of Environmental Technology Management, College for Women, Kuwait University, P.O. B5969, Safat 13060, Kuwait
}

2. Impact of height and shape of building roof on air quality in urban street canyons, Mohamed F. Yassin, Volume 45, Issue 29, September 2011, Pages 52205229, Atmospheric Environment

In addition, Mr. Mohamed F. Yassin published this paper in Environmental Monitoring and Assessment without the consent of co-authors Zbynek Janour and Radka Kellnerova. Given the copyright and authorship issues involved, the Environmental Monitoring and Assessment article in question is being retracted. 